\title{
Isu Teologi Kontekstualisasi Terhadap Adat Batak
}

\author{
Robert Situmorang, ${ }^{1 *}$ David Martinus Gulo 2 , Yusak Hentrias Ferry ${ }^{3}$ Vicky Baldwin \\ Goldsmith Dotulong Paat ${ }^{4}$, Dwijo Saputro ${ }^{5}$ \\ 1,2,3,4, ${ }^{5}$ Prodi Teologi, STT Real Batam \\ situmorang15@gmail.com
}

\begin{abstract}
Batak customs were originally thought to have their roots and origins in the idol worship of "Sipelebegu", although the Bataknese themselves never refer them or their religion as Sipelebegu. This negative assessment resulted Bataknese rejecting the gospel and Christianity at that time. Due to the Batak society is strictly known in maintaining customs, this creates two type of groups according to their opinions of customs, such as those who greatly admire, and the one who strongly oppose the implementation of Batak customs. However, Bible does not confront against customs and cultures, but also does not accept everything in them. Therefore, Bible does not consider a custom to be superior than another, but each custom determines its own measure of truth and justice; then, customs must also submit to the gospel.
\end{abstract}

Keywords: customs, Batak customs, contextualization theology

\begin{abstract}
Abstrak
Adat Batak semula dianggap berakar dan bersumber pada penyembahan berhala "Sipelebegu", meskipun orang Batak sendiri tidak pernah menyebut diri atau agamanya sebagai Sipelebegu. Penilaian negatif tersebut mengakibatkan orang Batak pada masa itu menolak Injil dan Kekristenan. Sebab masyarakat Batak terkenal sebagai suku yang sangat ketat memelihara adat, membuat dua kelompok terbagi menurut anggapan mereka mengenai adat, yakni mereka yang sangat mengagumi dan menentang keras pelaksanaan adat Batak. Meski begitu, Alkitab tidak konfrontatif menentang adat-istiadat, tetapi juga tidak menerima semua hal dalam adat. Karena itu, Injil tidak menganggap adat yang satu lebih unggul dari adat yang lain, melainkan masing-masing adat menetapkan ukuran kebenaran dan keadilannya sendiri; kemudian, adat juga harus tunduk pada Injil.

Kata kunci: adat, adat Batak, teologi kontekstualisasi
\end{abstract}




\section{PENDAHULUAN}

Perkembangan Adat merupakan hasil karya manusia dalam mengatur kehidupannya serta relasi antarsesama agar memiliki ketertiban dan keteraturan untuk menuju kesejahteraan bersama. Suatu kompleks dari ide-ide, gagasan, nilai-nilai, norma-norma, peraturan dalam kehidupan bermasyarakat tertentu. Sebenarnya sudah merupakan persoalan klasik sejak dulu, ketika para misionaris Jerman datang ke Tanah Batak. Pada mulanya mereka menilai negatif semua budaya dan adat Batak karena menganggap berakar dan bersumber pada penyembahan berhala "Sipelebegu."

Orang Batak sendiri tidak pernah menyebut diri atau agamanya sebagai Sipelebegu. Walaupun memiliki sistem religi yang menyatu dengan budaya, berpusat pada pemujaan terhadap Debata Mulajadi Nabolon jelas tidak sama dengan Debata Jahowa atau Allah yang diberitakan di Alkitab. Penilaian yang negatif dan konfrontatif tadi mengakibatkan orang Batak pada masa itu menolak Injil dan Kekristenan. Lambat laun para utusan zending atau misionaris itu melakukan banyak studi, lalu mempelajari nilai-nilai adat Batak dan melihat ada banyak hal dalam adat Batak yang juga positif dan indah.

\section{METODE}

Salah satu jenis penelitian bila dilihat dari tempat pengambilan data adalah penelitian kepustakaan. Disebut penelitian kepustakaan karena data-data atau bahan-bahan yang diperlukan dalam menyelesaikan penelitian tersebut berasal dari perpustakaan baik berupa buku, ensklopedi, kamus, jurnal, dokumen, majalah dan lain sebagainya. ${ }^{1}$

Penelitian kepustakaan merupakan suatu jenis penelitian yang digunakan dalam pengumpulan informasi dan data secara mendalam melalui berbagai literatur, buku, catatan, majalah, referensi lainnya, serta hasil penelitian sebelumnya yang relevan, untuk mendapatkan jawaban dan landasan teori mengenai masalah yang akan diteliti. Sumber data bersifat kepustakaan, atau berasal dari berbagai literatur, di antaranya buku, jurnal, surat kabar, dokumen pribadi, dan lain sebagainya. ${ }^{2}$ Sumber data dalam penelitian kepustakaan dibedakan menjadi dua, yakni sumber primer dan sumber sekunder. Sumber primer adalah sumber data pokok yang langsung dikumpulkan peneliti dalam dari objek penelitian, sedangkan sumber sekunder adalah sumber data tambahan yang menurut peneliti menunjang data pokok. ${ }^{3}$

Untuk memudahkan dalam penelitian kepustakaan tentunya seorang peneliti dituntut untuk mengenal dan memahami organisasi dan tata kerja (2014). 68

${ }^{1}$ Nursapia Harahap, "PENELITIAN KEPUSTAKAAN," Jurnal Iqra' 8, no. 1

${ }^{2}$ R. Poppy Yaniawati, Penelitian Studi Kepustakaan, Lingkungan Dosen IKIP Unpas, 2020, hlm. 12

${ }^{3}$ Ibid, hlm.16 
perpustakaan. Hal ini adalah penting agar lebih mudah memperoleh dan mengakses bahan-bahan atau sumber-sumber yang dibutuhkan. ${ }^{4}$ Sistem pelayanan perpustakaan, biasanya ada dua macam yaitu system tertutup dan sistem terbuka. Pada perpustakaan yang menerapkan sistem tertutup, peminjam tidak dibenarkan mengambil buku secara langsung. Peminjam dapat melihat nama buku, pengarang dan identitas lainnya pada katalog yang disediakan. Sedangkan sistem terbuka, peminjam dapat langsung mencari dan memilih buku atau sumber yang dibutuhkannya ke dalam ruangan buku (Surakhmad, 1982). Dengan adanya berbagai sistem perpustakaan dan tata kerja yang berbeda, maka bagi seorang peneliti kepustakaan tetapi juga penting juga bagi para peneliti lapangan. ${ }^{5}$

\section{HASIL DAN PEMBAHASAN}

Kontekstualisasi teologi menurut John Titaley terjadi ketika manusia memahami kehidupan dengan kesadaran bahwa Tuhan ikut terlibat dalam kehidupannya sehari-hari meliputi budaya dengan menyertakan Tuhan, kitab suci, ilahi, politik, dan lain-lain. ${ }^{6}$

Menurut Stephan Bevans, kontekstualisasi teologi adalah upaya untuk memahami Iman Kristen dipandang dari segi suatu konteks tertentu. Apa yang membuat teologi itu kontekstual adalah pengakuan teologi itu akan sumber teologi selain teks kitab suci dan tradisi yaitu pengalaman manusia sekarang ini. $^{7}$

Secara etimologi, teologi kontekstual adalah refleksi dari individu dalam konteks hidupnya atas Injil Yesus Kristus, maksudnya ialah tentang bagaimana Injil yang sudah ada dan utuh itu dibubuhi sampul yang baru yang bertujuan untuk memberikan keseimbangan melalui refleksi teologis dari penerima Injil (individu) tersebut. Setiap individu yang merefleksikan proses teologi kontekstual akan memperoleh pemahaman, penerimaan, pendirian dan keseimbangan terhadap kejadian atau peristiwa dari kenyataan yang dikondisikan berdasarkan kebudayaan dan sejarah manusia dengan situasi yang dialami saat ini. ${ }^{8}$

Dalam penerapannya Teologi Kontekstual mengalami proses kontekstualisasi. Proses tersebut tampak dengan timbulnya keyakinan individu terhadap sesuatu yang diperoleh melalui proses berpikir, sehingga

\footnotetext{
${ }^{4}$ Harahap, "PENELITIAN KEPUSTAKAAN."

${ }^{5}$ Ibid. 69

${ }^{6}$ John Titaley, Dekonstruksi Dan Rekonstruksi Teologi (Salatiga: Yayasan Bina Darma, 2006). 191-193

${ }^{7}$ Stephen Bevans, Model-Model Kontekstualisasi (Maumere: Ledalero, 2002). 2

${ }^{8}$ Y Tomatala, Teologi Kontekstual (Suatu Pengantar) (Malang: Gandum Mas, 1996). 2
} 
memperoleh pengetahuan melalui aktivitas mengingat, menalar dan analisa. ${ }^{9}$ Pengalaman kontekstualisasi merupakan sumber dalam berteologi, perbedaan cara berpikir dalam memahami fenomena yang ada menjadikan teologi kontekstual hadir sebagai penutup atau pelindung yang bersifat subjektif juga bersifat relatif. Akan tetapi pada kenyatannya setiap individu pasti akan tetap terikat dengan tradisi karena secara historis hal tersebut merupakan asal-usul dan sumber sejarah. ${ }^{10}$

Dasar dari Teologi Kontekstual merupakan inkulturasi yang berhubungan dengan pemberdayaan budaya setempat yang relatif tradisional sebagai sarana untuk berkomunikasi tentang kabar sukacita. ${ }^{11}$ Tentunya mengenai adat batak, selain pentingnya kontekstualisai juga perlu di rekonstruksi kembali pandangan tentang bagaimana bentuk-bentuk historis dari praktik-praktik Kristen diadaptasi dengan persekutuan komunitas ke dalam konteks yang muncul, agar pengalaman ibadah dapat memfasilitasi pertemuan antara para orang percaya, komunitas mereka, dan yang Ilahi. ${ }^{12}$ Gereja mestinya memperluas lensa keberadaannya untuk memadang budaya local. Sebagaimana Allah menyatakan diri-Nya dan berinkarnasi melalui wahyu dalam Alkitab sebagai sang pencipta, sehingga Allah menjadikan kehendak-Nya yang abadi dan menciptakan manusia. Penekanan utamanya adalah Allah merupakan penggerak utama atas kontekstualisasi, dimulai ketika Allah menyatakan diri-Nya dan semuanya yang ada berasal dari-Nya. ${ }^{13}$

Kontekstualisasi dinyatakan dalam konteks budaya total dari suatu masyarakat yang berkembang oleh kreativitas manusia dan refleksi teologis dinyatakan lewat filter budaya dan akan seimbang dengan pemahaman/penerimaan yang terbungkus dalam kebudayaan. ${ }^{14}$ Manusia diciptakan untuk berkreativitas dalam berbudaya dan menjadikan Wahyu Allah sebagai dasarnya. Terdapat dua hal yang dapat dipahami dalam pernyataan tersebut yaitu; hubungan Allah sebagai pencipta dan bertanggungjawab atas penyataan diri-Nya dan manusia yang menerima pernyataan-diri Allah melalui filter kebudayaan. ${ }^{15}$

\footnotetext{
${ }^{9}$ Ibid. 73

${ }^{10}$ Bevans, Model-Model Kontekstualisasi. 2-3

${ }^{11}$ Emanuel Gerrit Singgih, Berteologi Dalam Konteks (Yogyakarta: BPK Gunung Mulia, 2000). 17

${ }^{12}$ Fredy Simanjuntak and Yudhy Sanjaya, "Amanat Penggembalaan Dalam Ruang Virtual," Thronos 1, no. 2 (2020): 99-114.

13 Tomatala, Teologi Kontekstual (Suatu Pengantar). 12

${ }^{14}$ Ibid. 18

${ }^{15}$ Ibid. 13
} 
Dalam pemahamannya, teologi kontekstual memiliki dua sisi, yang pertama; setiap individu berhadapan dengan konteks, budaya dan agama tradisional; di sisi lainnya setiap individu bergumul dengan konteks modernisasi yang menyebabkan perubahan terhadap nilai dan kebiasaan setiap individu. Terdapat beberapa konteks yang mempengaruhi teologi konteksual, diantaranya konteks Alkitab, konteks tradisi sistematis dan konteks kita masa kini. ${ }^{16}$ Proses kontekstualisasi terjadi ketika seseorang mampu untuk memposisikan diri di tengah lingkungannya, namun tidak harus berubah total agar menjadi sama dan diterima oleh lingkungannya. ${ }^{17}$

Masyarakat Batak terkenal sebagai suku yang sangat ketat memelihara adat. Pranata kehidupan sosial orang Batak tidak pernah terlepas dari adat. Itu sebabnya ada orang mengatakan bahwa kehidupan tidak bisa dipisahkan dengat adat. Bagi mereka yang menghiraukan adat disebut tidak beradat atau 'naso maradat'. Bertolak belakang dibanding bila disebut tidak beriman atau 'ndang adong haporseaonmu' yang umumnya dihiraukan. Sikap seperti ini menunjukkan bahwa adat sangat dijungjung tinggi. Praktik dan penerapan adat Batak tersebut tidak hanya terlihat di kampung halaman (Bona Pasogit) saja. Di perantauan, sikap seperti itu juga pekat terasa. Salah satu buktinya ialah ketika melaksanakan suatu acara adat, gedung-gedung pertemuan Batak akan berjubel.

Belakangan ini dapat diamati bahwa paling tidak ada dua kelompok yang sangat kontras dalam memberi respon terhadap adat.

- Pertama, kelompok yang sangat mengagumi adat Batak, bahkan menganggap seperti seolah-olah tanpa salah dan menjunjung tinggi adat sebagai standar kehidupan yang benar, menjadikan adat sebagai agama, bahkan memperlakukan adat Batak berada setara dengan kitab suci.

- Kedua, kelompok yang menentang keras pelaksanaan adat Batak, menganggap identik dengan pekerjaan setan dan occultisme. Kelompok ini memandang seolah-olah tidak ada sesuatu yang baik di dalamnya, alias semuanya jahat.

Dalam Alkitab, kita akan menemukan bahwa Injil tidak konfrontatif menentang adat-istiadat, tetapi juga tidak menerima semua hal yang terdapat dalam adat. Ada begitu banyak studi kasus yang bisa digali di dalam Alkitab. Adat yang positif misalnya, keturunan Lamekh bernama Yabal, ahli membuat tenda dan memelihara ternak; Yubal, adiknya, ahli memainkan kecapi dan

\footnotetext{
${ }^{16}$ Ibid. 18-19

${ }^{17}$ Fransiska Stepani Hutajulu, "Kajian Teologi Kontekstual Perubahan Bentuk Persembahan Kerja Rani Di GBKP Runggun Yogyakarta" (Universitas Kristen Satya Wacana, 2019). 9
} 
seruling (Kejadian 4:20-21), demikian juga Daud adalah orang yang ahli memainkan kecapi. Kreativitas membuat tenda, beternak serta keahlian memainkan seruling dan kecapi adalah bagian dari peradaban manusia—seni budaya pada masa itu.

Hakim-Hakim 18:7 misalnya, dapat dilihat bahwa rakyat yang diam di sana, orang Sidon, hidup dengan aman dan tenteram. Bani Dan menemukan rakyat Lais di daerah wilayah Efraim hidup dalam damai menurut adat Sidon. Dalam Perjanjian Baru, Yesus menghadiri pesta pernikahan di Kana sesuai adat-istiadat Yahudi (Yohanes 2:1-11). Yesus disunat sesuai hukum adat Yahudi (Lukas 2:21-40), berpakaian sesuai adat Yahudi, dikuburkan sesuai adat-istiadat Yahudi (Matius 19:40).

Rasul Paulus juga terlibat dalam adat-istiadat Yahudi (Galatia 1:14, "Dan di dalam agama Yahudi aku jauh lebih maju dari banyak teman yang sebaya dengan aku diantara bangsaku, sebagai orang yang sangat rajin memelihara adat istiadat nenek moyangku."), tetapi juga menasihatkan kepada jemaat (Kolose 2:8) agar jangan ditawan dengan filsafat kosong dan palsu menurut ajaran turun temurun "Paradosis" (adat) dan roh-roh dunia. Sekalipun setelah pertobatannya, Rasul Paulus tidak memiliki semangat dan motivasi yang sama terhadap adat-istiadat. Namun, tidak terlihat pula ia menolak ataupun meninggalkan adat tersebut. Sebaliknya, dalam usaha memberitakan Injil Kristus, dia berusaha mengadaptasi dirinya dengan adat di lingkungan seperti yang tertulis dalam 1 Korintus 9:19-23; tujuannya ialah untuk memenangkan sebanyak mungkin orang. Maka, ia harus menyesuaikan diri dengan adat setempat. Ia peka terhadap adat setempat supaya Injil tetap relevan tetapi orang-orang tunduk dan hidup di bawah hukum Kristus agar Injil yang disampaikan itu tetap murni. Paulus memakai sarana adat sebagai pendekatan untuk mencapai Injil sebagai tujuan.

Dalam Alkitab memperlihatkan ada kebiasaan negatif pada adat yang ditentang oleh Allah, misalnya pada 2 Raja-Raja 17:7-8, tertulis: "Hal itu terjadi karena Israel telah berdosa kepada Tuhan, Allah mereka, yang telah menuntun mereka dari tanah Mesir dari kekuasaan Firaun, raja Mesir, dan karena mereka telah menyembah allah lain, dan telah hidup menurut adat istiadat bangsa-bangsa yang telah dihalau Tuhan dari depan orang Israel, dan menurut ketetapan yang dibuat raja-raja Israel.". Dalam Perjanjian Baru, kita dapat membaca bahwa Yesus sering menegur orang-orang Yahudi yang hidup secara legalistik dalam pelaksanaan adat istiadat. Misalnya yang tertulis pada Lukas 7:9: "Sungguh pandai kamu mengesampingkan perintah Allah, supaya kamu dapat memelihara adat istiadatmu sendiri." 
Dari pandangan Alkitab itu, kita bisa mengklasifikasikan adat dalam tiga dimensi yaitu:

- Pertama, adat yang bertentangan dengan Injil, misalnya: poligami, upacara mendoakan orang mati, praktik-praktik spiritisme (pemujaan terhadap arwah orang mati), ocultisme, animisme, dan dinamisme; Bertenung dan meramal (Ulangan 18:9-12).

- Ke dua, adat yang netral, artinya tidak dilarang tapi juga tidak dianjurkan, misalnya: cara berpakaian (ulos), sopan santun, etika sopan santun, cara makan-cara duduk dan cara bersalaman.

Ke tiga, adat yang sejalan dengan ajaran Alkitab, misalnya: hormat kepada orangtua (Keluaran 20:12), tidak boleh menikah dengan saudara kandung atau semarga (Imamat 20:17), tidak boleh berzinah (Ulangan 22:22), tidak boleh mencuri, istri hormat kepada suami (Efesus 5:22), peraturan pergaulan laki-laki dan wanita, hubungan seks pra-nikah (Efesus 5:3-5), memberi sedekah atau peduli dengan orang miskin (Matius 25:31-46), sifat gotong royong, dan bertolong-tolongan menanggung beban (Galatia 6:2).

\section{KESIMPULAN}

Adat memiliki keindahan dan kebaikan tetapi juga memiliki kelemahan. Injil tidak menganggap adat yang satu lebih unggul dari adat yang lain, melainkan masing-masing adat menetapkan ukuran kebenaran dan keadilannya sendiri. Adat harus tunduk kepada Injil. Kita harus secara aktif, kreatif, konstruktif, serta terus-menerus membaharui adat Batak agar tetap relevan dengan zaman dan lingkungan. Adat bukan suatu hal yang tidak bisa berubah tapi sesuatu yang dinamis.

Kita dituntut memahami Alkitab dengan benar dan memahami adat dengan benar, dengan mengidentifikasikan diri dengan lingkungan tetapi juga hidup berpadanan dengan Injil Kristus (Filipi 1:27). Unsur-unsur adat yang sifatnya netral dan tidak bertentangan dengan iman tetap dipertahankan, tetapi unsur yang tidak sesuai dengan Firman Allah harus diubah atau tinggalkan. Selanjutnya, orang percaya harus bersifat selektif, tidak serta-merta menolak adat tersebut atau menerima semuanya walaupun bertentangan dengan Injil. Kita harus memahami sejauh mana kita mampu menghayati adat dan ungkapannya secara mendalam dan mendasar, bukan sekadar kulit luarnya, sekaligus memajukan dan meningkatkan kualitas iman.

\section{KEPUSTAKAAN}

Bevans, Stephen. Model-Model Kontekstualisasi. Maumere: Ledalero, 2002. 
Harahap, Nursapia. "PENELITIAN KEPUSTAKAAN." Jurnal Iqra' 8, no. 1 (2014).

Hutajulu, Fransiska Stepani. "Kajian Teologi Kontekstual Perubahan Bentuk Persembahan Kerja Rani Di GBKP Runggun Yogyakarta." Universitas Kristen Satya Wacana, 2019.

Simanjuntak, Fredy, and Yudhy Sanjaya. "Amanat Penggembalaan Dalam Ruang Virtual.” Thronos 1, no. 2 (2020): 99-114.

Singgih, Emanuel Gerrit. Berteologi Dalam Konteks. Yogyakarta: BPK Gunung Mulia, 2000.

Titaley, John. Dekonstruksi Dan Rekonstruksi Teologi. Salatiga: Yayasan Bina Darma, 2006.

Tomatala, Y. Teologi Kontekstual (Suatu Pengantar). Malang: Gandum Mas, 1996. 